\title{
General insight into cancer: An overview of colorectal cancer (Review)
}

\author{
SHIEKHAH MOHAMMAD ALZAHRANI, HUDA ABDULAZIZ AL DOGHAITHER and AYAT BADR AL-GHAFARI
}

Department of Biochemistry, Faculty of Science, King Abdulaziz University, Jeddah 21589, Saudi Arabia

Received June 30, 2021; Accepted September 28, 2021

DOI: $10.3892 / \operatorname{mco} .2021 .2433$

\begin{abstract}
Cancer is currently among the leading causes of mortality globally. Colorectal cancer (CRC) ranks second among the most common types of cancer in terms of mortality worldwide. This type of cancer arises from mutations in the colonic and rectal epithelial tissues that target oncogenes, tumor suppressor genes and genes related to DNA repair mechanisms. The aim of the present review was to provide an explanation of CRC classification, which is carried out according to the histological subtype, location and molecular pathways implicated in its development. The pathogenic mechanisms implicated in CRC may involve one of three different molecular pathways: Chromosomal instability, microsatellite instability and cytosine preceding guanine island methylator phenotype. In addition, a variety of mutated genes associated with CRC, which affect certain signaling pathways, including DNA mismatch repair, cell cycle checkpoints and apoptotic pathways, were discussed. Moreover, a brief description of the risk factors and the symptoms associated with CRC was also provided. Finally, the treatment approaches to CRC were outlined.
\end{abstract}

\section{Contents}

1. Introduction

2. Colorectal cancer

3. Classification of colorectal cancer

4. Signalling pathways altered by colorectal cancer oncogenes

5. Risk factors for colorectal cancer

6. Treatment of colorectal cancer

7. Conclusion

Correspondence to: Dr Huda Abdulaziz Al Doghaither, Department of Biochemistry, Faculty of Science, King Abdulaziz University, Building 7, Girls Campus, Abdullah Al Sulimania Street, Jeddah 21589, Saudi Arabia

E-mail: haldoghaither@kau.edu.sa

Key words: colorectal cancer, classifications, molecular pathways, signaling pathways, risk factors and treatment

\section{Introduction}

Cancer is categorized as a leading cause of mortality worldwide in the 21 st century. According to the World Health Organization (WHO), cancer was the first or second leading cause of death before the age of 70 years in most countries in 2015 (1), whereas new cancer cases and cancer-related deaths are expected to reach 21.4 and 13.2 million annually, respectively, by 2030 (2). Overall, the incidence and mortality rates of cancer are rapidly increasing worldwide. The reasons for these increases are complex, but mainly reflect aging, population growth and changes to the major risk factors for cancer, several of which are related to socioeconomic development $(1,3,4)$.

The classic model of cancer envisaged a normal cell transforming into an atypical or dysplastic cell with progression into an invasive or malignant cell (5). Cancer can be defined as uncontrolled cell proliferation and division. Cancer cells can spread and invade other parts of the body through the blood and lymphatic circulation (6). At the cellular level, cancer classically develops through three defined stages: Initiation, promotion and progression. The first stage, initiation, occurs when genetic, metabolic and carcinogenic factors damage the DNA molecule $(7,8)$. Carcinogens, including radiation, chemicals and viruses, have been found to induce cancer in both experimental animals and humans $(7,9)$. Carcinogens act by damaging DNA and inducing mutations (7) via a process called carcinogenesis, which involves the activation of oncogenes and/or the deactivation of tumor suppressor genes, leading to uncontrolled cell cycle progression and inactivation of apoptosis (10). The second stage of cancer development is promotion. This is a prolonged stage, which begins with the proliferation of cells that become defective during the initiation process. Progression is the third and final stage, which is described as the metastasis of tumor cells that develop during the proliferation step (8). However, a simple genetic mutation is not sufficient to drive cancer development; therefore, the multiple-hit hypothesis indicates that cancer is the result of accumulated genetic mutations in the DNA of a cell. This proposed hypothesis was first reported by Nordling and later by Knudson (11-13).

Cancer cells differ from normal cells in several aspects. Cancer cells are less stringently regulated compared with normal cells (7). The uncontrolled proliferation of cancer cells results from accumulated abnormalities affecting a 
number of the cell regulatory mechanisms (7), which reflect the behavior that distinguishes cancer cells from their normal counterparts (6,7). Furthermore, several genetic and molecular alterations are characteristic of cancer $(6,14)$. Hanahan and Weinberg (6) described six hallmarks that explain the behavior of cancer cells: Self-sufficiency in growth signals, insensitivity to growth-inhibitory (antigrowth) signals, evasion of programmed cell death (apoptosis) mechanisms, limitless replicative potential, sustained angiogenesis, and tissue invasion and metastasis (6). Additionally, the aforementioned authors published the next generation of cancer hallmarks, to which they added two more hallmarks, namely reprogramming of cellular metabolism and evasion of elimination by the immune system, reaching a total of eight of cancer cell characteristics. Underlying these hallmarks are genome instability and inflammation (15). Multiple signaling pathways are affected simultaneously by tumor progression, such as irregularities in DNA repair, cell cycle, apoptosis and redox balance (16).

As mentioned above, cancer can develop from abnormal proliferation of any of the different cell types in the body; thus, there are $>100$ distinct types of cancer, which can differ substantially in their behavior and response to treatment (7).

The term 'tumor' is used to describe the abnormal proliferation of cells, and it may be either benign or malignant. The distinction between benign and malignant tumors is the most important issue in cancer pathology (7). The characteristics differentiating malignant from benign lesions are well established and comprise a rapid rate of growth, increased cell turnover, invasive growth, metastasis, and lymphatic and/or vascular channel invasion $(5,17)$. Benign tumors remain confined to their original location, without invasion of surrounding normal tissues or distant spread and dissemination (7). However, malignant tumors can both invade surrounding normal tissues and spread (metastasize) to other parts of the body via the circulatory or lymphatic systems $(7,10)$. Only malignant tumors are referred to as cancers, and the ability to metastasize is what makes cancer dangerous. The spread of malignant tumors to distant body locations frequently makes them resistant to treatment. Over one million cases of cancer are diagnosed in the USA each year, and more than half a million Americans succumb to cancer annually (7).

The majority of cancers fall into one of three main groups: Carcinomas, sarcomas and leukemias or lymphomas. Carcinomas are malignant tumors arising from epithelial tissues and comprise $\sim 90 \%$ of human cancers (7). Sarcomas are rare solid tumors arising from connective and skeletal tissues $(7,18)$. Leukemias and lymphomas arise from stem cells in the bone marrow and from immune system cells, respectively $(7,19)$. Tumors are classified according to the tissue of origin and the type of cell involved. Cancers arising from 10 different body sites, including the breast, lung, colon/rectum, bladder, skin and uterus, as well as lymphomas and leukemias, account for $>75 \%$ of the total incidence of cancer. Although there are numerous types of cancer, only a few occur frequently. The four most common cancer types, accounting for over half of the total cancer cases, are breast, prostate, lung and colorectal cancer (CRC) (7). The focus of the present review was the different types of CRC.

\section{Colorectal cancer}

In all fields of clinical practice and research, colon cancer (CC) and rectal cancer ( $\mathrm{RC}$ ) are considered as a single tumor entity, referred to as CRC. The term CRC is based on three different aspects. The first aspect is the hypothesis that CC and RC develop in the large intestine, which is considered to be a single organ. The second aspect is the similar anatomical structure of the colonic and rectal walls, comprising the mucosa, muscular layer and, in part, the serosa, as well as their similar histology. The third aspect is the similar functions of the colorectal tract, involving stool concentration, fluid resorption, stool transportation and excretion (20). CC accounts for $72 \%$ and RC for $28 \%$ of all CRCs, although the incidence of CRC generally states both statistics jointly (13). CRC, mostly comprising adenocarcinoma of the colon and rectum, is defined as a transformation of the normal colonic and rectal epithelium to a precancerous lesion (adenomatous intermediate) and, eventually, to an invasive carcinoma (adenocarcinoma), which may spread to different distant organs and give rise to metastatic lesions, with the liver being the most frequently affected organ (21-24). This process requires an accumulation of genetic mutations that are either somatic (acquired) and/or germline (inherited) over a period of $10-15$ years $(23,24)$. The previous concept, referred to as 'colorectal carcinogenesis', is a multistep genetic process in which mutations of diverse genes accumulate during the progression from normal colorectal epithelium to adenoma to invasive carcinoma (25), which will be described later.

Globally, CRC ranks as the third most common type of cancer $(1,26)$ but ranks second in terms of mortality; it therefore poses a substantial health and economic burden (1). It has been predicted that the incidence of CRC will increase to $60 \%$ by the year 2030 , although its incidence has decreased to some extent (27), possibly due to increased cancer screening and improved available therapies (24). Over 1.8 million new CRC cases and 881,000 deaths were estimated to occur in 2018 worldwide for both sexes combined, representing $\sim 1$ in 10 cancer cases and fatalities (1).

Generally, cancer may begin to show symptoms and signs as it grows and expands. The clinical presentation of patients with adenocarcinoma varies based on the primary position of the tumor and the extent to which other organs are involved (28). Studies reported that most CRC patients who completed the questionnaires described various symptoms with differing frequencies. The most frequently occurring symptom was blood in the stool (32.8\%), followed by changes in bowel habits $(28.9 \%)$, other symptoms, such as fatigue, decreased appetite, fever and nausea $(22.0 \%)$, and abdominal pain (16.3\%) (29). Blood in the stool was characterized as a symptom specific of CRC, whereas non-specific symptoms included fatigue, nausea, fever, decreased appetite (29), weight loss, abdominal pain and bowel obstruction (28).

\section{Classification of colorectal cancer}

CRC is usually classified according to histological subtype, location and molecular pathway involved (22). 
Histological subtypes of CRC. The histological subtype is defined according to the traditional WHO classification of CRC (22,30). A number of histological subtypes of CRC have been characterized, such as mucinous, medullary, signet ring cell, adenosquamous, spindle cell, micropapillary, serrated and cribriform comedo-type (31). All these variants can be further differentiated from colorectal adenocarcinoma (24). Colorectal adenocarcinoma and three of these variants are discussed in more detail below.

Colorectal adenocarcinoma. The vast majority of CRCs are adenocarcinomas, accounting for $>90 \%$ of CRC cases worldwide. Adenocarcinomas are malignant neoplasms originating from the colorectal mucosal epithelial cells of the glands or glandular structures $(22,28,31,32)$.

Mucinous colorectal adenocarcinoma. Mucinous colorectal adenocarcinoma is the second most common subtype of CRC and is characterized by the presence of extracellular mucinous pools in at least $50 \%$ of the tumor volume. This subtype accounts for $5-20 \%$ of CRC cases worldwide (22,31-33). Carcinomas with a prominent mucinous component are usually labeled 'adenocarcinomas with mucinous features (mucinous adenocarcinoma)'. This type typically exhibits large glandular structures with extracellular mucinous pools $(31,34)$. A large number of mucinous adenocarcinomas are found in patients with hereditary non-polyposis CRC [HNPCC or Lynch syndrome (LS)] and they represent high-level microsatellite instability (MSI-H) tumors $(31,35)$.

Medullary CRC. The frequency of medullary CRC has been estimated to be $4 \%(22,36)$. This subtype is characterized by the combination of abnormal solid growth and an inflammatory reaction $(22,30)$. Medullary carcinoma is strongly correlated with MSI-H $(22,30,31,37,38)$, often in combination with mutations of the BRAF gene, which is encodes the B-Raf proto-oncogene serine/threonine-protein kinase $(22,30)$.

Signet ring cell CRC. Signet ring cell carcinomas are comparatively rare in colorectum, representing $<2 \%$ of all CRCs, and they are associated with a very poor outcome $(22,31,39)$. This type of carcinoma is characterized by the presence of $>50 \%$ of cancer cells with a signet ring-like morphology (31). Some signet ring CRCs may be MSI-H tumors (32).

Rare types of CRC. Other rare types of CRC that are not frequently encountered include neuroendocrine, squamous cell, adenosquamous, spindle cell and undifferentiated carcinomas $(24,31)$.

Classification of CRC according to location. CRC can also be classified according to its location along the colon. According to this classification, colon cancer is divided based on its embryological origin into midgut or proximal colon and hindgut or distal colon. This division also appears relevant in terms of outcome, as distal colon cancer usually has a more favorable outcome compared with proximal colon cancer $(22,40)$.

Classification of CRC according to molecular pathway. Molecular pathway classification has become increasingly important and plays a key role in CRC classification (22).
CRC occurs due to mutations that target oncogenes, tumor suppressor genes and genes linked to DNA repair mechanisms. In general, both genetic and epigenetic instability play a critical role in the occurrence and development of CRC (41). The pathogenic mechanisms implicated in CRC may include three different molecular pathways: Chromosomal instability (CIN), MSI and cytosine preceding guanine (CpG) island methylator phenotype (CIMP) pathways $(24,41,42)$.

CIN pathway. CIN is considered to be the classic, most common molecular pathway involved in the development of CRC and is responsible for $80-85 \%$ of all CRC cases $(22,41,43)$. CIN is a molecular alteration that is associated with an imbalance in the number of chromosomes, which leads to aneuploidy and loss of heterozygosity in tumors. Moreover, it can result from defects in different mechanisms, including chromosome segregation, telomere dysfunction and DNA damage response, which have an impact on genes that serve a key role in the maintenance of normal cell function $(41,44)$. CIN tumors are associated with sets of mutations in specific tumor suppressor genes and oncogenes [including adenomatous polyposis coli (APC), KRAS, PIK3CA, TGF- $\beta$ and TP53], which activate pathways crucial for CRC initiation and progression (44). The APC gene is a tumor suppressor gene that protects cells from malignant transformation (13). Inactivating mutations of $A P C$ lead to $\beta$-catenin translocation into the nucleus and drives the transcription of genes involved in carcinogenesis and cancer invasion $(41,44)$. In CIN CRC, inactivation of the $A P C$ gene occurs first and is followed by activating mutations of KRAS. The subsequent cancerous transformation is driven by additional mutations in the $T G F-\beta, P I K 3 C A$ and TP53 pathways (44). KRAS and PIK3CA are oncogenes that can cause cancer growth via the expression of oncoproteins, which, in turn, can cause an increase in protein activity, loss of regulation, or an increase in protein levels (13). However, mutational activation of $K R A S$ and $P I K 3 C A$ leads to a constant induction of MAPK, thus promoting cell proliferation. TP53 is a tumor suppressor gene that encodes the $p 53$ protein, the main cell-cycle checkpoint; therefore, TP53 mutational inactivation leads to an uncontrolled entry in the cell cycle $(41,44)$. In addition, CIN affects the $T G F-\beta$ pathway in CRC, which leads to defects in two important tumor suppressor genes, known as SMAD2 and SMAD4, the loss of which leads to apoptosis escape and deregulation of the cell cycle (41).

MSI pathway. The MSI pathway is the second most common molecular pathway involved the development of CRC (22). Microsatellites (MS), known as short tandem repeats, are short DNA sequences or tandem repeats (1-6 base pairs) found throughout the entire genome (present in both coding and non-coding regions) and represent $\sim 3 \%$ of the human genome (42). Owing to their repeated structure, the ability to repair MS is decreased in tumors with MSI. Therefore, they are highly susceptible to mutations; these mutations tend to accumulate in non-coding regions, as well as in coding MS (41,42,45). MSI is a molecular alteration pathway characterized by a hypermutable phenotype as a result of a defective DNA mismatch repair (MMR) system $(41,42)$. The DNA MMR system is a highly conserved biological pathway that corrects base-base mismatches, erroneous insertions and deletions 
created during DNA replication and recombination that have escaped the proofreading process (46). In tumor DNA, MSI is defined as the presence of alternate-sized repetitive DNA nucleotides that are not found in the corresponding germline DNA (42). In general, mutations in DNA MMR genes lead to a DNA MSI phenotype. MSI in tumors leads to the mutations of MMR genes, including MutL homologue $(M L H) 1$, MutS homologue $(M S H) 2, M S H 6$, and mismatch repair endonucleases PMS1 and PMS2 (47).

CIMP. Epigenetic instability is responsible for the third molecular pathway, the CIMP pathway, which is another common feature in CRC (41). CpG islands are short sequences within the genome found in promoter sites that have a greater number of cytosine and guanine (CG) residues and a higher frequency of $\mathrm{CpG}$ dinucleotides compared with other regions of the genome. Promoters, including $\mathrm{CpG}$ islands, are responsible for gene expression regulation of $>50 \%$ of human genes (48). DNA methylation, an epigenetic modification, is an enzymatic reaction that adds a methyl group $\left(-\mathrm{CH}_{3}\right)$ to a cytosine nucleotide (C) at the 5-position via the DNA methyltransferase (DNMT) enzyme to yield 5-methyl-C. The preferred substrate of the DNMT enzyme is commonly a CG dinucleotide sequence, known as CpG $(48,49)$. A CIMP tumor is characterized by vast hypermethylation (epigenetic change) of oncogene promoters (CpG island sites), resulting in the silencing of tumor suppressor genes and the loss of protein expression $(41,42,48)$. Several CIMP colorectal tumors exhibit the combined effect of genetic and epigenetic modifications that include the presence of $B R A F$ mutations as well as MSI (50), affecting the $B R A F$ and $M L H 1$ genes, respectively (24).

Classification of CRC according to mutation origin. Depending on the origin of the mutation, CRCs can be classified into three distinct groups: Sporadic CRC (SCC; 70\%), familial CRC (FCC; 25\%) and inherited CRC (ICC; 5\%) $(24,41,42)$.

SCC. The majority of CRCs are of the sporadic type. This involves $\sim 75 \%$ of CRC cases without obvious evidence of an inherited disorder (approximately three-quarters of patients have a negative family history) $(42,51)$. Thus, the definition of SCC is a carcinoma that arises from colorectal tissue without a known association with inherited diseases (germline causes), a family history of CRC, or inflammatory bowel disease (IBD) (52). SCC is a somatic genetic cancerous condition (52) that is caused by point mutations that become noticeable during a patient's lifetime, is not associated with inherited syndromes, and only affects single cells and their descendants (41). SCC is common among individuals aged $>50$ years $(24,53)$ and may be influenced by environmental factors, the patient's genetic background (52), dietary factors and aging (53). A CIN pathway is observed in $65-70 \%$ of SCC cases (44). Genetically, SCC is caused by multiple mutations that can target different genes. Specifically, SCC progresses through the accumulation of a series of abnormalities in tumor suppressor genes and oncogenes. An initiating mutation (inactivation) occurs in the $A P C$ gene, inducing the formation of non-malignant adenomas (polyps) that can ultimately transform to adenocarcinoma. This alteration is subsequently followed by mutations in the KRAS, TP53 and, finally, deleted in colorectal carcinoma
(DCC) genes $(41,54)$. Additionally, tumor suppressor genes require biallelic loss. Known as the 'two-hit' model, this is observed in the loss of the APC $5 q 21$ gene (80\% sporadic), the DCC/SMAD2-4 $18 q$ gene (73\% sporadic) and the TP53 $17 p$ gene (50-70\% sporadic) (24). Alteration of the $M L H 1$ gene via promotor hypermethylation is a frequent somatic mutation in MSI-H SCC (70-95\%) (42). Moreover, sporadic oncogene somatic mutations (RAS, SRC and $M Y C)$ are implicated in CRC. RAS mutation variants (HRAS, KRAS and NRAS) exhibit the greatest clinical relevance and are found in $50 \%$ of patients with SCC (24).

FCC. FCC accounts for $25 \%$ of all CRC cases. It occurs in the absence of an identifiable inherited syndrome and is often considered as sporadic $(24,41,42)$. First-degree relatives of individuals with a history of CRC are at a 2-3-fold greater risk of developing this type of cancer compared with that of the general population $(42,55)$.

ICC. ICC accounts for merely $5 \%$ of all CRC cases $(24,41,42)$. It is caused by inherited mutations that affect one of the alleles of the mutated gene. The hypothesis in ICC is that a point mutation in the other allele induces the transformation of the cancer cell and, thus, the development of carcinoma (41). The most common ICC subtypes are two syndromes: Familial adenomatous polyposis (FAP) and $\operatorname{HNPCC}(24,28,56)$.

FAP, an inherited CRC syndrome, is the most common hereditary polyposis syndrome. FAP is an autosomal dominant disorder with polyps mainly found in the proximal colon and rarely in the rectum $(42,57)$. FAP is characterized by the development of several potentially malignant polyps in the colon (58). For individuals with FAP, the estimated mean age for developing polyps is 35 years, and these individuals are at a high risk of developing CRC (57). The FAP syndrome is caused by a mutation (inactivation) in the $A P C$ gene $(42,56,59)$. The $A P C$ gene is a tumor suppressor gene that encodes the APC protein, which is a multifunctional protein responsible for controlling cell proliferation and preventing the development of tumors. Moreover, the physiological role of the APC protein is to regulate the $\beta$-catenin protein levels via degradation. The $\beta$-catenin protein serves a key role in cell signaling, transduction of Wnt signaling and cell proliferation by acting as a transcription factor for proliferation-related genes. However, a mutation in the $A P C$ gene leads to defective APC protein function, resulting in an accumulation of $\beta$-catenin in the cell. Insertions, deletions and nonsense mutations of the $A P C$ gene have been described as causes of FAP syndrome $(42,60)$. In addition to $A P C$ gene mutations, mutations of the KRAS, BCL-2, P53, $C O X-2$ and $D C C$ genes, among others, are also needed for cancer development (61).

HNPCC, also known as LS, is the most common hereditary CRC syndrome. LS is an autosomal dominant disorder caused by germline alterations (inherited mutations) in one of the alleles of DNA MMR genes and genes encoding DNA repair proteins, including $M L H 1, M S H 2, M S H 6, P M S 1$ and PSM2 $(31,56,62,63)$. Mutations of the $M S H 1$ and $M L H 2$ genes account for the majority of LS cases $(31,64)$. As previously mentioned, alterations in DNA MMR genes result in the development of a mutated phenotype known as MSI, which 
is a hallmark of LS $(42,65)$. Moreover, MSI-H is observed in $\sim 90 \%$ of LS-associated CRCs $(42,66)$.

Consensus molecular subtypes (CMS) of CRC. New molecular discoveries in CRC classification have been made based on reported gene expressions and simplified clinical translation. These involved four CMS (42) and a mixed group that cannot be further classified (22): i) CMS1 (MSI immune, 14\%), hypermutated, microsatellite unstable, defective DNA MMR system and strongly immunogenic; ii) CMS2 (canonical, 37\%), characterized by high CIN, epithelial, marked activation of Wnt (a protein that plays a crucial role in stem-cell differentiation and cell proliferation) and c-MYC (protein that regulates cell proliferation and apoptosis) signaling, and highest overall survival rate; iii) CMS3 (metabolic, 13\%), epithelial, evident metabolic dysregulation and KRAS mutation; and iv) CMS4 (mesenchymal, 23\%), characterized by $\mathrm{CpG}$ hypermethylation, prominent TGF- $\beta$ activation, stromal invasion and angiogenesis, and lowest survival rate $(22,24,41,42)$.

In addition to gene mutations within the types of $\mathrm{CRC}$, modifications in non-coding RNAs, such as long non-coding RNAs or microRNAs, may also be involved in several steps of the carcinogenesis pathway and function as biomarkers (41).

\section{Signaling pathways altered by colorectal cancer oncogenes}

The several aforementioned types of CRC harbor a variety of mutations in different genes. These mutations mainly affect three signaling pathways: The Wnt- $\beta$-catenin signaling pathway (related genes: $A P C, A X I N 2$ and $C T N N B 1$ ), the tyrosine kinase receptors (related genes: $A B L, A K T, K R A S$, LCK, SRC, RAF1, MOS and PIM1), and the TGF- $\beta$ signaling pathway (related genes: TGF $\beta R I I, S M A D 2$ and SMAD4). Other genes associated with CRC include DNA MMR (related genes: MLH1, MLH3, MSH2, MSH6, PMS1 and PMS2) and genes associated with cell cycle checkpoints and apoptotic pathways ( $B A X, B c l-2$ and $p 53$ ). In addition, it has been reported that genes related to the Hedgehog signaling pathway may also be affected in CRC (13).

\section{Risk factors for colorectal cancer}

A variety of risk factors are correlated with the incidence of $\mathrm{CRC}$, which is considered to be a heterogeneous disease $(42,56)$. Both genetic and environmental factors play a prominent role in the etiology of CRC and increase its risk $(28,51)$, while other risk factors are associated with a modestly increased risk of CRC (24).

Inherited genetic risk. Hereditary factors are one of the CRC risk factors that cannot be controlled (56). Several hereditary CRC syndromes increase the risk of CRC (28). The most common such syndromes are FAP and HNPCC, also known as LS $(24,28,56)$. Approximately $5 \%$ of all CRC cases can be attributed to these two inherited conditions (24).

Personal and family history. The personal and family history of patients with CRC and the presence of adenomatous polyps are associated with a high risk for synchronous and metachronous primary CRC. In addition, a personal history of IBD
(Crohn's disease and ulcerative colitis) is associated with an increased risk of CRC $(24,28)$.

Race and ethnicity. There are wide variations in CRC survival that can be race- and ethnicity-dependent. For example, in the USA, both Native Americans and African Americans have a greater risk of developing CRC and exhibit lower survival across all stages of CRC compared with Hispanic and white Americans (67).

Sex. The risk of CRC is slightly higher among men compared with that observed in women (28). Across all ages in every nation, men have a 1.5 -fold greater risk of developing CRC compared with women. Furthermore, in comparison to men, women are more susceptible to right-sided colon cancer, which has a more aggressive phenotype compared with left-sided colon cancer $(67,68)$.

Age. Age is also a CRC risk factor that cannot be controlled $(41,51,56)$. Over $90 \%$ of CRC cases occur in individuals aged $\geq 50$ years $(69,70)$. The incidence rate of $\mathrm{CRC}$ is $>50$-fold higher in individuals aged 60-79 years compared with those aged $<40$ years $(70,71)$.

Comorbidities. Comorbidities that increase the risk of CRC include diabetes mellitus/insulin resistance, childhood cancer survivors who underwent abdominal irradiation, uncontrolled acromegaly, cholecystectomy, long-term immunosuppression following kidney transplantation (24), cystic fibrosis, and patients with prostate cancer who undergo androgen deprivation therapy (67).

Environmental factors and lifestyle. It has been reported that there are strong associations between environmental and lifestyle factors and CRC development (56). Low socioeconomic status linked with poor medical care increases the risk of CRC. Nutritional practices include high meat consumption, red and processed meat consumption $(24,56)$, diets high in fat, and diets low in fruit, vegetables and fiber are also associated with CRC risk (56). In addition, low physical activity, excess body weight and obesity have been reported to increase the risk of CRC $(51,56)$. Cigarette smoking and heavy alcohol consumption may also be associated with an increased risk of developing CRC $(24,28,56)$.

\section{Treatment of colorectal cancer}

Early diagnosis is a key factor in improving the survival of patients with CRC (29). Several types of cancer may be treatable if detected at an early stage, before metastases develop $(72,73)$. Generally, the standard modes of cancer treatment are chemotherapy, surgery and radiation (74), or a combination of these for advanced-stage disease (75). The choice of treatment for CRC follows a multimodal approach that depends on tumor-related characteristics, such as location, size, extent of cancer metastasis and the health status of the patient $(41,76)$. In general, various treatment approaches for primary and metastatic (mtCRC) have emerged, providing patients with more options; these approaches involve laparoscopic surgery for primary CRC (early-stage), more 
aggressive resection of mtCRC (such as pulmonary and liver metastases), radiotherapy for $\mathrm{RC}$, neoadjuvant chemotherapy and palliative chemotherapy (51). Surgical resection is the main modality for patients with potentially curable and localized early-stage CRC $(24,41,77)$; however, depending on the disease stage, neoadjuvant chemotherapy and/or radiotherapy may be administered before or after surgery (77). Among the various types of solid tumors, it is only in patients with CRC that the survival rate can be increased by the surgical removal of distant metastases from organs such as the lungs and liver. The survival of patients with unresectable mtCRC can be increased by treatment with systemic chemotherapy (21). In CRC, the use of chemotherapy is usually combined with monoclonal antibodies against EGFR and VEGF to inhibit tumor growth and angiogenesis $(13,24)$. A palliative systemic approach is used for non-surgical CRC cases (patients with late-stage mtCRC) to improve the quality of life and prolong life expectancy (24). To increase treatment effectiveness and reduce the side effects of traditional chemotherapy, alternative therapies are currently under investigation, such as anti-inflammatory drugs, gold-based drugs, agarose macrobeads and probiotics (41). However, despite the advances in the treatment of CRC, late diagnosis of the disease and the lack of safety and effectiveness of chemotherapy remain major obstacles in treatment efficacy (78).

\section{Conclusion}

CRC is a heterogeneous disease that includes multiple carcinogenic pathways. In the majority of the cases, CRC-related mortality may be reduced by early diagnosis (colonoscopy), applying existing knowledge on cancer prevention and effective treatment. Although there are numerous molecular mutations implicated in CRC, more research is required to fully elucidate the basis of CRC. Avoiding CRC risk factors holds the most promise for preventing its development among different populations worldwide. Finally, CRC studies that focus on the discovery and development of new therapies that are less aggressive and more effective than conventional treatment are needed to ameliorate the overall survival and quality of life of patients with CRC in the future.

\section{Acknowledgements}

Not applicable.

\section{Funding}

No funding was received.

\section{Availability of data and materials}

Not applicable.

\section{Authors' contributions}

SMA and HAA deigned the present review, collected information and wrote the manuscript. HAA and ABA wrote and reviewed the manuscript. All the authors have read and approved the final version of the manuscript.

\section{Ethics approval and consent to participate}

Not applicable.

\section{Patient consent for publication}

Not applicable.

\section{Competing interests}

The authors declare that they have no competing interests.

\section{References}

1. Bray F, Ferlay J, Soerjomataram I, Siegel RL, Torre LA and Jemal A: Global cancer statistics 2018: GLOBOCAN estimates of incidence and mortality worldwide for 36 cancers in 185 countries. CA Cancer J Clin 68: 394-424, 2018.

2. Center M, Siegel R and Jemal A: Global Cancer Facts and Figures 2010. American Cancer Society, Atlanta, GA, 2011.

3. Omran AR: The epidemiologic transition: A theory of the epidemiology of population change. Milbank Mem Fund Q 49: 509-538, 1971.

4. Gersten $\mathrm{O}$ and Wilmoth JR: The cancer transition in Japan since 1951. Demogr Res 7: 271-306, 2002.

5. Idikio HA: Human cancer classification: A systems biology-based model integrating morphology, cancer stem cells, proteomics, and genomics. J Cancer 2: 107-115, 2011.

6. Hanahan D and Weinberg RA: The hallmarks of cancer. Cell 100: 57-70, 2000.

7. Cooper GM: The Cell: A Molecular Approach. In: The Development and Causes of Cancer. 2nd edition. Sinauer Associates, Sunderland, MA, 2000. Available from: https://www.ncbi.nlm.nih. gov/books/NBK9839/.

8. Doll R and Peto R: The causes of cancer: Quantitative estimates of avoidable risks of cancer in the United States today. J Natl Cancer Inst 66: 1192-1308, 1981.

9. Blackadar CB: Historical review of the causes of cancer. World J Clin Oncol 7: 54-86, 2016.

10. Sarkar S, Horn G, Moulton K, Oza A, Byler S, Kokolus S and Longacre M: Cancer development, progression, and therapy: An epigenetic overview. Int J Mol Sci 14: 21087-21113, 2013.

11. Nordling CO: A new theory on the cancer-inducing mechanism. Br J Cancer 7: 68-72, 1953.

12. Knudson AG Jr: Mutation and cancer: Statistical study of retinoblastoma. Proc Natl Acad Sci USA 68: 820-823, 1971.

13. Centelles JJ: General aspects of colorectal cancer. ISRN Oncol 2012: 139268, 2012.

14. Fimognari C, Lenzi M, Ferruzzi L, Turrini E, Scartezzini P, Poli F, Gotti R, Guerrini A, Carulli G, Ottaviano V, et al: Mitochondrial pathway mediates the antileukemic effects of hemidesmus indicus, a promising botanical drug. PLoS One 6: e21544, 2011.

15. Hanahan D and Weinberg RA: Hallmarks of cancer: The next generation. Cell 144: 646-674, 2011.

16. Chaudhary S, Devkar RA, Bhere D, Setty MM and Pai KSR: Selective cytotoxicity and pro-apoptotic activity of stem bark of wrightia tinctoria (Roxb.) R. Br. in cancerous cells. Pharmacogn Mag 11 (Suppl 3): S481-S487, 2015.

17. Van Raamsdonkvan CD, Bezrookove V, Green G, Bauer J, Gaugler L, O'Brien JM, Simpson EM, Barsh GS and Bastian BC: Frequent somatic mutations of GNAQ in uveal melanoma and blue naevi. Nature 457: 599-602, 2009.

18. Hoang NT, Acevedo LA, Mann MJ and Tolani B: A review of soft-tissue sarcomas: Translation of biological advances into treatment measures. Cancer Manag Res 10: 1089-1114, 2018.

19. Davis AS, Viera AJ and Mead MD: Leukemia: An overview for primary care. Am Fam Physician 89: 731-738, 2014.

20. Paschke S, Jafarov S, Staib L, Kreuser ED, MaulbeckerArmstrong C, Roitman M, Holm T, Harris CC, Link KH and Kornmann M: Are colon and rectal cancer two different tumor entities? A proposal to abandon the term colorectal cancer. Int J Mol Sci 19: 2577, 2018. 
21. Li M, Zhang N and Li M: Capecitabine treatment of HCT-15 colon cancer cells induces apoptosis via mitochondrial pathway. Trop J Pharm Res 16: 1529-1536, 2017.

22. IARC: Colorectal cancer screening. Vol. 17. IARC Handb Cancer Prev, pp1-300, 2019. Available from: http://publications.iarc. fr $/ 573$.

23. Recio-Boiles A, Kashyap S, Tsoris A and Babiker HM: Rectal Cancer. [Updated 2020 Dec 17]. In: StatPearls. StatPearls Publishing, Treasure Island,FL, 2021. Available from: https://www. ncbi.nlm.nih.gov/books/NBK493202/.

24. Recio-Boiles A and Cagir B: Colon cancer. [Updated 2021 Jan 25]. In: StatPearls. StatPearls Publishing, Treasure Island, FL, 2021 Available from: https://www.ncbi.nlm.nih.gov/books/NBK470380/.

25. Li L, Su N, Cui M, Li H, Zhang Q, Yu N, Wu S and Cao Z: Activation-induced cytidine deaminase expression in colorectal cancer. Int J Clin Exp Pathol 12: 4119-4124, 2019.

26. Siegel R, DeSantis C and Jemal A: Colorectal cancer statistics, 2014. CA Cancer J Clin 64: 104-117, 2014.

27. Guinney J, Dienstmann R, Wang X, De Reyniès A, Schlicker A, Soneson C, Marisa L, Roepman P, Nyamundanda G, Angelino P, et al: The consensus molecular subtypes of colorectal cancer. Nat Med 21: 1350-1356, 2015.

28. Mullangi S and Lekkala MR: Adenocarcinoma. [Updated 2021 Feb 22]. In: StatPearls. StatPearls Publishing, Treasure Island, FL, 2021. Available from: https://www.ncbi.nlm.nih. gov/books/NBK562137/.

29. Jensen LF, Hvidberg L, Pedersen AF and Vedsted P: Symptom attributions in patients with colorectal cancer. BMC Fam Pract 16: 115, 2015

30. Nagtegaal ID, Odze RD, Klimstra D, Paradis V, Rugge M, Schirmacher P, Washington KM, Carneiro F and Cree IA; WHO Classification of Tumours Editorial Board: The 2019 WHO classification of tumours of the digestive system. Histopathology 76 : 182-188, 2020

31. Fleming M, Ravula S, Tatishchev SF and Wang HL: Colorectal carcinoma: Pathologic aspects. J Gastrointest Oncol 3: 153-173, 2012.

32. Hamilton SR and Aaltonen LA (eds): Carcinoma of the colon and rectum. In: Pathology and Genetics of Tumors of the Digestive System. IARC Press, Lyon, pp105-119, 2000.

33. Hugen N, van Beek JJ, de Wilt JH and Nagtegaal ID: Insight into mucinous colorectal carcinoma: Clues from etiology. Ann Surg Oncol 21: 2963-2970, 2014.

34. Verhulst J, Ferdinande L, Demetter P and Ceelen W: Mucinous subtype as prognostic factor in colorectal cancer: A systematic review and meta-analysis. J Clin Pathol 65: 381-388, 2012.

35. Leopoldo S, Lorena B, Cinzia A, Gabriella DC, Angela Luciana B Renato C, Antonio M, Carlo S, Cristina P, Stefano C, et al: Two subtypes of mucinous adenocarcinoma of the colorectum: Clinicopathological and genetic features. Ann Surg Oncol 15 $1429-1439,2008$

36. Nagtegaal ID and Hugen N: The increasing relevance of tumour histology in determining oncological outcomes in colorectal cancer. Curr Colorectal Cancer Rep 11: 259-266, 2015.

37. Alexander J, Watanabe T, Wu TT, Rashid A, Li S and Hamilton SR: Histopathological identification of colon cancer with microsatellite instability. Am J Pathol 158: 527-535, 2001.

38. Hinoi T, Tani M, Lucas PC, Caca K, Dunn RL, Macri E, Loda M, Appelman HD, Cho KR and Fearon ER: Loss of CDX2 expression and microsatellite instability are prominent features of large cell minimally differentiated carcinomas of the colon. Am J Pathol 159: 2239-2248, 2001.

39. Hugen N, Verhoeven RH, Lemmens VE, van Aart CJ, Elferink MA, Radema SA, Nagtegaal ID and de Wilt JH Colorectal signet-ring cell carcinoma: Benefit from adjuvan chemotherapy but a poor prognostic factor. Int J Cancer 136 333-339, 2015.

40. Petrelli F, Tomasello G, Borgonovo K, Ghidini M, Turati L, Dallera P, Passalacqua R, Sgroi G and Barni S: Prognostic survival associated with left-sided vs right-sided colon cancer: A systematic review and meta-analysis. JAMA Oncol 3: 211-219, 2017.

41. Mármol I, Sánchez-de-Diego C, Pradilla Dieste A, Cerrada E and Rodriguez Yoldi MJ: Colorectal carcinoma: A general overview and future perspectives in colorectal cancer. Int J Mol Sci 18 $197,2017$.

42. Nojadeh JN, Behrouz Sharif S and Sakhinia E: Microsatellite instability in colorectal cancer. EXCLI J 17: 159-168, 2018

43. Grady WM and Carethers JM: Genomic and epigenetic instability in colorectal cancer pathogenesis. Gastroenterology 135 1079-1099, 2008.
44. Pino MS and Chung DC: The chromosomal instability pathway in colon cancer. Gastroenterology 138: 2059-2072, 2010.

45. Ellegren H: Microsatellites: Simple sequences with complex evolution. Nat Rev Genet 5: 435-445, 2004.

46. Jiricny J: The multifaceted mismatch-repair system. Nat Rev Mol Cell Biol 7: 335-346, 2006.

47. Boland CR and Goel A: Microsatellite instability in colorectal cancer. Gastroenterology 138: 2073-2087.e3, 2010.

48. Nazemalhosseini Mojarad E, Kuppen PJ, Aghdaei HA and Zali MR: The CpG island methylator phenotype (CIMP) in colorectal cancer. Gastroenterol Hepatol Bed Bench 6: 120-128, 2013.

49. Lao VV and Grady WM: Epigenetics and colorectal cancer. Nat Rev Gastroenterol Hepatol 8: 686-700, 2011.

50. Weisenberger DJ, Siegmund KD, Campan M, Young J, Long TI, Faasse MA, Kang GH, Widschwendter M, Weener D, Buchanan D, et al: $\mathrm{CpG}$ island methylator phenotype underlies sporadic microsatellite instability and is tightly associated with BRAF mutation in colorectal cancer. Nat Genet 38: 787-793, 2006.

51. Kuipers EJ, Grady WM, Lieberman D, Seufferlein T, Sung JJ, Boelens PG, van de Velde CJ and Watanabe T: Colorectal cancer. Nat Rev Dis Primers 1: 15065, 2015.

52. Carethers JM and Jung BH: Genetics and genetic biomarkers in sporadic colorectal cancer. Gastroenterology 149: 1177-1190.e3, 2015.

53. Arvelo F, Sojo F and Cotte C: Biology of colorectal cancer. Ecancermedicalscience 9: 520, 2015.

54. Yamagishi H, Kuroda H, Imai Y and Hiraishi H: Molecular pathogenesis of sporadic colorectal cancers. Chin J Cancer 35: 4, 2016.

55. Lin OS: Colorectal cancer screening in patients at moderately increased risk due to family history. World J Gastrointest Oncol 4: 125-130, 2012

56. Haggar FA and Boushey RP: Colorectal cancer epidemiology: Incidence, mortality, survival, and risk factors. Clin Colon Rectal Surg 22: 191-197, 2009.

57. Laurent S, Franchimont D, Coppens JP, Leunen K, Macken L, Peeters M, Plomteux O, Polus M, Poppe B, Sempoux C, et al: Familial adenomatous polyposis: Clinical presentation, detection and surveillance. Acta Gastroenterol Belg 74: 415-420, 2011.

58. Lynch HT and de la Chapelle A: Hereditary colorectal cancer. N Engl J Med 348: 919-932, 2003.

59. Wilmink AB: Overview of the epidemiology of colorectal cancer. Dis Colon Rectum 40: 483-493, 1997.

60. Bogaert J and Prenen H: Molecular genetics of colorectal cancer. Ann Gastroenterol 27: 9-14, 2014.

61. Zeichner SB, Raj N, Cusnir M, Francavilla M and Hirzel A: A de novo germline APC mutation (3927del5) in a patient with familial adenomatous polyposis: Case report and literature review. Clin Med Insights Oncol 6: 15-23, 2012.

62. Papadopoulos N, Nicolaides NC, Wei YF, Ruben SM, Carter KC, Rosen CA, Haseltine WA, Fleischmann RD, Fraser CM, Adams MD, et al: Mutation of a mutL homolog in hereditary colon cancer. Science 263: 1625-1629, 1994.

63. Lynch HT, Lynch PM, Lanspa SJ, Snyder CL, Lynch JF and Boland CR: Review of the Lynch syndrome: History, molecular genetics, screening, differential diagnosis, and medicolegal ramifications. Clin Genet 76: 1-18, 2009.

64. Lynch HT and Shaw TG: Practical genetics of colorectal cancer. Chin Clin Oncol 2: 12, 2013.

65. Dekker E, Tanis PJ, Vleugels JL, Kasi PM and Wallace MB: Colorectal cancer. Lancet 394: 1467-1480, 2019.

66. Boland CR and Shike M: Report from the Jerusalem workshop on Lynch syndrome-hereditary nonpolyposis colorectal cancer. Gastroenterology 138: 2197.e1-e7, 2010.

67. Rawla P, Sunkara T and Barsouk A: Epidemiology of colorecta cancer: Incidence, mortality, survival, and risk factors. Prz Gastroenterol 14: 89-103, 2019.

68. Kim SE, Paik HY, Yoon H, Lee JE, Kim N and Sung MK: Sexand gender-specific disparities in colorectal cancer risk. World $J$ Gastroenterol 21: 5167-5175, 2015.

69. U.S. Department of Health and Human Services: What you need to know about cancer of the colon and rectum. National Cancer Institute; 1st edition, 2006.

70. Ries LAG, Melbert D, Krapcho M, Stinchcomb DG, Howlader N, Horner MJ, Mariotto A, Miller BA, Feuer EJ, Altekruse SF, et al (eds): SEER cancer statistics review, 1975-2005, National cancer institute. Bethesda, MD, 2008.

71. American Cancer Society: Colorectal cancer facts and figures special edition 2005. Atlanta: American Cancer Society, 2005. 
72. Duffy SW, Tabar L, Olsen AH, Vitak B, Allgood PC, Chen TH Yen AM and Smith RA: Absolute numbers of lives saved and overdiagnosis in breast cancer screeninq, from a randomized trial and from the breast screening programme in England. J Med Screen 17: 25-30, 2010.

73. Smith RA, Cokkinides V and Eyre HJ: Cancer screening in the United States, 2007: A review of current guidelines, practices, and prospects. CA Cancer J Clin 57: 90-104, 2007.

74. Blecher E, Chaney-Graves K, DeSantis C, Edwards B, Ferlay J, Forman D, Grey N, Harford J, Kramer J, McMikel A, et al: Global cancer facts and figures. American Cancer Society, Atlanta, GA, USA, 2011.

75. Samee A and Selvasekar CR: Current trends in staging rectal cancer. World J Gastroenterol 17: 828-834, 2011.
76. Mohammadian M, Zeynali S, Azarbaijani AF, Khadem Ansari MH and Kheradmand F: Cytotoxic effects of the newly-developed chemotherapeutic agents 17-AAG in combination with oxaliplatin and capecitabine in colorectal cancer cell lines. Res Pharm Sci 12: 517-525, 2017.

77. Redondo-Blanco S, Fernández J, Gutiérrez-del-Río I, Villar CJ and Lombó F: New insights toward colorectal cancer chemotherapy using natural bioactive compounds. Front Pharmacol 8: 109, 2017

78. Van Cutsem E, Cervantes A, Adam R, Sobrero A, Van Krieken JH, Aderka D, Aranda Aguilar E, Bardelli A, Benson A, Bodoky G, et al: ESMO consensus guidelines for the management of patients with metastatic colorectal cancer. Ann Oncol 27: 1386-1422, 2016. 